\title{
Systemic Functional Theory: A Pickax of Textual Investigation
}

\author{
Taofeek Dalamu \\ Department of English, University of Lagos, Akoka, Yaba, Nigeria \\ E-mail: lifegaters@yahoo.com
}

Received: 21-11-2016

Published: 01-05-2017
Accepted: 16-01-2017

doi:10.7575/aiac.ijalel.v.6n.3p.187
Advance Access Published: March 2017

URL: http://dx.doi.org/10.7575/aiac.ijalel.v.6n.3p.187

\begin{abstract}
The study examines Systemic Functional Theory (SFT) as a tool of examining text, and perhaps, text of any dimension as long as it falls within the grammatical organs of the clause. The author provides explanations for the theory from its relevant source(s). The chronological appreciation involves the efforts of Saussure, Firth, Malinowski, Hjelmslev, etc. However, Halliday's insight seems prominent and upon which Systemic Functional Theory receives a global status that it has assumed today. Halliday constructs numerous concepts e.g. lexicogrammar, processes, cohesion, coherence, system, system network with background from traditional grammar and sociological tokens. In addition to that, the three metafunctions are characterized as its core operational concepts. Out of these, the mood system serves as the instrument of analysis of Psalm one utilized in this endeavor as a case study. Although the clauses fall within the profile of the indicative and imperative, the study reveals that some of the structures are inverted in order to propagate the intended messages. To that end, there are inverted indicative clauses expressed as inverted declarative statements, inverted imperative questions and inverted negativized polarity. In sum, Systemic Functional Theory is a facility for explaining different shapes of texts.
\end{abstract}

Keywords: Clause, Mood system, Systemic Functional Theory, Text, Three Metafunctions

\section{Introduction}

Language, either spoken or written, is an embodiment of meaning-making. The purpose of language construction and dissemination from one source to another is to perform one or more functions among its users. That is, among social actors executing a communicative project in society. It means that when meaning is aborted from language as an interactional facility the essence of its manifestation becomes a bit of mess. Language, a powerful magic (Firth 1958:185), is a weave of texts in multifaceted ways. The nature and texture of a processed text depend largely of the addresser and addressees, the topic on course, the setting, the knowledge of the language in use, the objective of its use, etc. Irrespective of the context that characterized the text, text remains the custodian of semantic influences in any language. That is why linguists (e.g. Halliday \& Hasan 1985) are highly interested and their insistence in investigating texts in order to explicate their contents in relation to meaning. The analysis of the text of a language cannot be done haphazardly; it must be procedural. This demand gives rise to theoretical machinery that have the capacity to serve as utilitarian tools of analysis. Therefore, linguistics theories have been designed to play crucial roles in the realms of textual considerations. In a more succinct way, Ferdinand de Saussure created an endless path for linguistics investigations through appropriate theoretical concepts. Some of the most prominent of de Saussure's concepts are syntagmantic, paradigmatic, la langue, parole, sign, signifier and signified. This pioneering effort, in the world of linguists, has constructed what de Beaugrande (1991:2) refers to as a theoretical balance sheet. Among others, Edward Sapir, Leonard Bloomfield, Kenneth Pike, Louis Hjelmslev, Roman Jakobson, John Austin, John Firth and Noam Chomsky have contributed immensely to linguistics concepts of textual examinations.

Of significance is the effort of Michael Halliday in the constructs of linguistics terminology and applications. Halliday's insightful thoughts motivate Ravelli to argue that,

One of the most exciting features of the systemic functional theory (henceforth: SFT), is the extent to which one can actually say relevant and useful things about what is happening in language, that is, the extent to which you can do something with analysis' (Ravelli 2001: 27).

Ravelli has found that there are 'exciting features' in SFT and these features are tools that could strongly assist researchers in generating meaning, to a large extent, from any form of text engagements. The pivotal relevance of these features, so to say, is hanging on the systemic three 'goal posts' which are widely known as Metafunctions. Each metafunction wears a linguistic lens at which it sees meaning in its own perspective via a separate but distinct 'semiotic address' (Halliday \& Matthiessen 2004: 62) of one or more systems in a particular cell. The three dimensions of meanings that the metafunctions harmoniously generate in a text have made the text to be understood as an amalgamated entity of meaning derivatives. 
To support the claim of the compliant nature of the SFT in textual analysis, the author has decided to use Psalm one (1) as a text, and the application of the SFT as a litmus test of its meaning potential and resources. The choice of Psalm one as a test tube is because: (i) it is not a recent phenomenon but rather older than the theory; (ii) its choice of word is pungent; (iii) it has a religious inclination; (iv) it is the beginning of, perhaps, a popular book in the Bible among its readers; (v) it has twofold nature of tones - one for the righteous and one for the sinner; and (vi) it is globally known for its generational availability. In a simple term, the study demonstrates the versatility of SFT in examining any form of text in any context. This can sensitize researchers and students to appreciating SFT for their textual clarifications.

\title{
1.1 What is SFT?
}

Systemic Functional Theory is Halliday's. It specializes in textual illuminations. SFT projects text as a functional edifice in a particular social arena. By 'functional', it refers to text as an entity (as a human being) doing a particular work in a particular environment. In the Chapelle sense of the matter SFT rescues linguists for a long time constraints in textual analysis. She says that,

\begin{abstract}
Applied linguists study language use in context such as the contexts associated with specialized registers (e.g. business or academic), context of language assessment (e.g, speaking tests and writing assignments). As a consequence many applied linguists are interested in linguistic theory that takes into account the contextual dimensions of language (Chapelle 1998:1).
\end{abstract}

It is from this aspiration that SFT came to be and located itself in the linguistic domain of an empirical tool of investigation. Chapelle adds further that, it views language as a social semiotic, a resource that people use to accomplish their purposes by expressing meanings in context. In respect of that, it has been mentioned that the value of a theory lies in the use that can be made of it, and 'I have always considered a theory of language to be essentially consumer oriented' (Halliday 1985: 7). This perspective from the major figure of SFT is refreshing to applied linguists who grew up on a diet of linguist oriented structural transformation (Chapelle 1998:1). There is no doubt that many textual analysts, and most especially linguists, are comfortable with the ideas of Halliday because of the multipurpose assistance that the theory renders on textual analysis. The in-depth knowledge of the theory will assist the analysts to speed up the rate and ratio at which their texts are conveniently and socially investigated. It seems that SFT has advanced the analysis of the texts from the mundane into a high altitude.

\subsubsection{Historical Evolvement}

Historically, the study of language in general is attached to divergent and numerous historical views. So, SFT is not left out of this coffin. Besides, an understanding of SFT has confirmed to us that it sprouts out of the popular traditional grammar. It has been mentioned also that to have a complete and broader know-how of SFT one needs to be reasonably familiar with the traditional word classes of grammar (Halliday \& Matthiessen 2004: 52). Subject to this, one can comfortably argue that some of the terms of the SFT are anchored on the traditional grammar along with some sociological terms. In agreement with that opinion, Bloor and Bloor provide a soft-landing for the argument that 'Although modern grammars may differ from traditional in very significant ways, they all owe something to this tradition' (Bloor \& Bloor 2004: 234). In short, it will not only be an unproductive exploration, but also a heart-rending exercise if someone should attempt to completely separate systemic grammatics from the traditional notion of linguistics founding fathers. Halliday claims that;

The theory on which this description is based, systemic theory, follows in the European functional tradition. It is largely based on Firth's system-structure theory, but derives more abstract principles from Hjelmslev and owes many ideas to the Prague school. The organization concept is that of the 'system', which is used essentially in Firth's sense of a functional paradigm but developed into the formal construct of a 'system network'. This system network is a theory about language as a resource for making meaning (Halliday 1985:xxvi).

What is developed to be SFT today, Halliday posits, emanated from somewhere. In order words, SFT has founding fathers. Its anchor is on the Prague School. Some of the founding fathers are Hjelmslev, Malinowski and Firth. No matter how tiny and sketchy their contributions could be to this linguistic address, some of their notional concepts are noticeably felt till this day. System is coined by Firth as he argues that the grammar of a language is polysystemic, a system of systems; and Malinowski coined also the term Context of Situation around 1921 (Bloor \& Bloor 2004: 244245). These are conceptual frameworks that construct SFT as a functional device.

Systemic linguistics has its roots in Firthian linguistics, and so it not a surprise that it is a type of system structure theory (Martin 1992: 4). Halliday aims higher than some of his colleagues and predecessors and he really believes in the idea that a language is a system where everything hangs together (Davidse 2001: 106; Hudson 1996). Halliday harnesses Furth's somewhat sketchy suggestions about system of meaning explications. At the same time, he develops Malinowski's ideas about Context of Situation with greater rigor into an elaborate network representing the choices available to the users of language (Bloor \& Bloor 2004: 245). The development sequence of the SFT could be represented thus,

Hjelmslev $\longrightarrow$ Malinowski $\longrightarrow$ Firth $\longrightarrow$ Halliday $\longrightarrow$ Global Systemicists

The expansion of this course besides Halliday has rested on the shoulders of many other scholars across Europe, Australia, America and beyond that have picked interest in SFT's developments. Some of the other leading figures in SFT are Matthiessen, Martin, the Bloors, Thompson, Eggins, Lemke, McGregor and Unsworth. From the stance of 
Fawcett, he says that, 'Many linguists with interest in formal linguistic theory have a general awareness that Halliday proposed a number of insightful ideas about the nature of language... from a functional perspective (2000: 1). In fact, Halliday is usually referred when related issues on SFT are discussed. SFT, no doubt, is a well-rooted linguistic tool that has taken an important position in the language research.

\subsubsection{Text in SFT}

Language is used in so many dimensions as a means of communication. The author is aware of the Sign Language in which any feature that is characteristically found in spoken languages has a counterpart in the Sign Language and at the same time, has its own dialect in different regions (Yule 1985: 164-5). In this discussion, I will limit the use of language to spoken language and written language. This is adopted because SFT is an analytical tool that impinges on text as a medium in which its concepts operate. Basically, for a spoken language to be analyzed, it has to be converted into a written text. It must be concretized. With that inevitable rule, the study migrates to the concept of text as an important item. Therefore, a text 'is any instance of language in use' (Thompson 2004: 10); that is, a language in use that is dependent on context in either spoken or written form. From another perspective, 'A text is any stretch of language regardless of length that is spoken or written for the purpose of communication by real people in actual circumstances (Bloor \& Bloor 2004: 5). Bloor and Bloor have shed some lights on the characteristics of a text of analysis in SFT. The unveiling descriptions of text have persuaded the writer to characterize it with the following traits: (i) it is either spoken or written, (ii) it communicates meaningful messages, (iii) it has a purposeful context and (iv) it has a length. The most striking phenomenon in the qualities of a text is that, it communicates meaningful messages. This could be the reason that inspires Halliday and Hasan to have suggested that a text is a semantic unit (1976:2; 1985; see Schiffrin, Tannen \& Hamilton 2002). It is the meaning characterization of a text that propels scholars to refer to it as an authentic product of social interaction and a unified whole... in terms of meanings, not in terms of form' (see Eggins 2004: 23 \& 28). Text is not just a spoken device; it is a communicative vehicle to the audience. And in as much as that, people must deduce meaning from the text otherwise such discourse will tend to be what Bittner called 'semantic noise' (2002: 10). If a French text is given to a Yorùbá speaker who does not understand it to raise a comment, until such a text is translated into the Yorùbá language that the person understands, it is not yet a text. For it to become a text, it must be interpreted or perhaps given to anyone who could derive meanings from the piece of language in use.

In consonance with that, Halliday and Matthiessen argue that, the term text refers to any instance of language, in any medium that makes sense to someone who knows the language (Halliday \& Matthiessen 2004: 3). A text is an authentic text when the participants involved - speaker/listener or writer/reader - are able to make meanings out of it. A text is actually functional. The nucleus of the textual function is the connectivity involves with the Syntagmatic organization of the linguistic organs of a clause. The various parts of a text integrate into a coherent and cohesive unified whole and relate to the wider context of our speech or writing. The systemicists accordingly devote more attention to the treatment of texts than to the analysis of isolated sentences. Because of this preoccupation with texts, the concepts of coherence and cohesion play a central role (Trask \& Stockwell 2008: 293) in communication and textual considerations. The concepts of coherence and cohesion are not within the scope of this study.

\subsection{Clause: The Crux of Analysis}

Basically, there is an argument that 'we are more likely to arrive at interesting and useful descriptions of English if we investigate authentic text' (Bloor \& Bloor 2004: 5). In SFT, the authenticity of a text is realized simply within the clause that accommodates it. Irrespective of the length of the language use, it must have grammatical units and constituents of the clause. 'These units form the core of what is called the rank-scale, that is, the hierarchical arrangement of grammatical constituents. Clauses are made up of groups and phrases which are made up of words' (Ravelli 2000 31). The figure below adapted from Thompson is sufficed for the explanation.

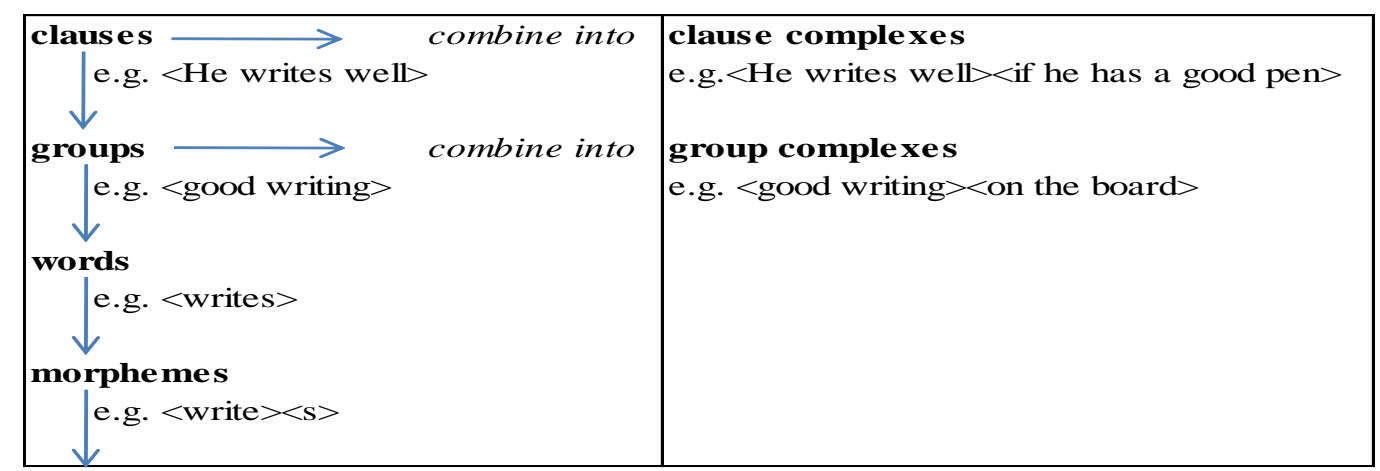

Figure 1. The rank scale (Source: Thompson 2004:23)

The stretch of the grammar of a language is rank-scaled as shown in Figure 1 above. In that wise, the grammar of a clause is seen as the powerhouse of a language. Besides, there are possibilities of having group complexes and clause complexes in cases where a unit is embedded in the other. From Figure 1 above, the highest constituent is the clause classified as the 'hub of the grammar' (Ravelli 2000: 29). A clause is the stretch of morphemes + words + groups. Picking from the orientation of the traditional notion, scholars have given different definitions to the clause/simple sentence. Let us consider some of the descriptions. A clause/simple sentence is a group of words containing a subject 
and a predicate. A sentence is (i) a group of words that begins with a capital letter and ends with a full stop; and (ii) it is a group of words that makes a single complete statement and contains a verb (Akere 1990:65). A clause/simple sentence consists of a group of words... one half of the group is the subject, the other half is the predicate. The predicate contains a finite verb. (Egbe 1998:28).

These various perspectives on the clause are given to clear the waves on what is really known as a clause in SFT. The clause is not necessarily meant to have a subject or a finite. The subject can be intrinsic, yet, it is a clause. In the case of an indicative clause, yes, the writer agrees to the submission that a subject may, most times, textually be featured. But in terms of the imperative clause, one can argue that the subject may be intrinsic. It may be featured or may not be featured. The issue of the finite is also dangling. So, what is known as a clause is a bit wider and advanced than the sample definitions above. It may sound so difficult for a single definition to capture what a clause is. The definitions above are particularly coherent with the indicative clauses from the mood system. In addition to the points of views of Akere (1990) and Egbe (1996a, 1996b), the author puts the lenses on the mood system on the levels of delicacy that clauses explicate in English. Thus, a clause (independent) could be determined with the following parameters:

\begin{tabular}{|c|c|}
\hline $1 \mathrm{Wh} \wedge \varnothing$ & \\
\hline $2 \mathrm{Wh}^{\wedge}$ Finite & Interrogative \\
\hline $3 \mathrm{Wh}^{\wedge}$ Finite $^{\wedge}$ Subject & Structures \\
\hline 4 Finite $^{\wedge}$ Subject & \\
\hline 5 Subject $^{\wedge}$ Finite & Declarative \\
\hline 6 Subject $\wedge^{\wedge}$ Fused Element & Structures \\
\hline
\end{tabular}

$7 \varnothing^{\wedge}$ Predicator [unmarked]

8 Don’t $\wedge$ Predicator [unmarked]

9 Subject $(\text { You })^{\wedge}$ Predicator [marked]

10 Positive Polarity (Do $)^{\wedge}$ Predicator [marked]

11 Negative Polarity $(\text { Don’t })^{\wedge}$ Subject $(\text { You })^{\wedge}$ Predicator [marked]

Imperative

Structures

$12 \varnothing^{\wedge}$ Let's ^ Predicator

13 Positive Polarity (Let's) ${ }^{\wedge}$ Predicator

14 Negative Polarity (Let's) $\wedge^{\wedge}$ Predicator

The structures above have shown that the nature of a clause could be delimited in terms of the functional specificity. It is possible to comprehend a clause through the windows of both ideational and textual metafunctions. However, the concept of clause systems is perhaps easiest to grasp when we are dealing with the interpersonal metafunction (Thompson 2004: 36). It is shown that four types of clause structures are realized through the interrogative, two are realized through the declarative and eight are realized through the imperative. See the following examples.

(i) Why? (ii) Who will dance? (iii) What are you saying? (iv) Are you a Professor of English? (v) Wale is very friendly. (vi) Tosin read that text in her class. (vii) Encourage yourself. (viii) Don't joke with your education. (vix) Tobi, play on. (x) Do rise up above your challenges. (xi) Don't rise up above your challenges. (xii) Let's pray now. (xiii) Do let's pray for him. (xiv) Don't let's pray for him.

Examples (i) - (iv) are interrogative clauses that ask questions. Examples (v) and (vi) are declarative clauses that make statements. Examples (vii) - (xiv) are imperative clauses that command. Offer is not featured here because it is part of the declarative clause and this paper, at this point in time, is not dealing with the interpersonal metafunction in its entirety but used it as a sample on how clauses are objectified.

The first clause why has a Subject but there is no Finite. The sixth clause has a Subject Tosin with an inbuilt Finite past. The seventh clause has no Subject at all - though one may agree that the subject is 'hanging in the air' - but there is no Finite.

The clause sequence explained could be placed in parallel with what is called the grammar of a language. It has been posited that 'Grammar is one of the subsystems of a language; more specifically, it is the system of wordings of a language' (Halliday \& Matthiessen 2004: 1). It is in the understanding of this paper that grammar is one of the resourceful systems that a language possesses. It then means that it is an integral part of the other symbolic arms of a language whose system of wordings is applied to create meaning. Task \& Stockwell add that;

The single greatest insight the approach to language called Structuralism was the recognition that a language is best viewed as a system of elements, with each system being chiefly defined by its place within the system, by the way it is related to other elements... the overall system of a language consists of a number of systems and subsystems all of which overlap in various ways (Trask \& Stockwell 2008: 290-1). 
One can deduce from Trask and Stockwell that a-system-of-elements contain a set of options coming together with an entry condition, such that if the entry condition is satisfied one option from the set must be selected (Bloor \& Bloor 2004: 245; cf. Halliday 1972). A system, in this technical sense, Halliday \& Matthiessen (1999: 17) assert, is a point of choice in the construction of a clause.

According to these scholars (e.g. Trask \& Stockwell 2008), a language, for some decades, has been examined from a conceptual framework of a system. The overall system is not in isolation, it is rather interconnected with the other subsystems in relation to structural chain formations for adequate meaning comprehensions. This chain-relationship is what is known as the system of a language. In one way or another, the system could also be overlapped in their structural organizations. Though the system of choice is available to the speaker/writer in several options, however, only one model of strong preference can be selected for use at a particular time. There is no one speaker/writer that has the linguistic capacity to choose more than one choice when 'sharing the logical magic' (Firth 1957: 185).

Furthermore, let us reach out once again to the examples from the clause sequential realizations used above to demonstrate that they are systems that are parts of the grammar of English. The study uses the table below to express the dimensions of this claim. The table indicates the systemic differences that are located in the indicative (declarative and interrogative) and imperative.

Table 1. The differences in indicative and imperative clauses

\begin{tabular}{lll}
\hline $\mathbf{S} / \mathbf{N}$ & Indicative & Imperative \\
\hline $\mathbf{1}$ & $\begin{array}{l}\text { It has a mandatory Finite except in (i) } \\
\text { above. }\end{array}$ & No Finite. \\
\hline $\mathbf{2}$ & It has a Subject. & No Subject. \\
\hline $\mathbf{3}$ & It has a choice in Tense (past/present). & No choice in Tense. \\
\hline $\mathbf{4}$ & $\begin{array}{l}\text { It has a choice in person which is } \\
\text { indicated through the Subject. }\end{array}$ & $\begin{array}{l}\text { If the Subject is available at all, it is express as you and } \\
\text { let's }\end{array}$ \\
\hline $\mathbf{5}$ & $\begin{array}{l}\text { The choice being made negotiates } \\
\text { information in a dialogue. }\end{array}$ & $\begin{array}{l}\text { The choice being made negotiates goods and services in } \\
\text { a dialogue. }\end{array}$
\end{tabular}

The imperative clauses do not normally operate within the context of either a Subject or a Finite. However, few domains of use allow for this. Let's for instance, is used as a subject in the imperative but 'it is best interpreted as a 'wayward' form of the Subject you and I' (Halliday \& Matthiessen 2004: 139). An imperative clause commands absolutely, so the Finite could be irrelevant in it. The relevant time in the context refers to the future only. Thompson (2004:56) has critically said that 'In interpersonal terms, an imperative is presented as not open to negotiation'. It is obvious that sometimes, the addresser may respond to the command or decline it. For example, Come along with me. The addresser may either agree by following the speaker or by not following him. He could respond verbally by saying, Okay, I will come along with you or No, I won't come along with you. In a case of such, an imperative is a bit open to negotiation.

The indicative clause usually has a Subject. An arm of the indicative, that is, the declarative clause has a mandatory Subject-cum-Finite. The second arm, that is, the interrogative may not, once in a while, have the Finite in a text. In a dialogue, the speaker may say, I will come to your house. The addresser could quickly respond thus, Why? When? These wh-questions are employed to probe further on the discourse. As appeared, the why and when interrogative clauses are use to investigate the reason and the time the speaker will be coming to his house. These exceptional cases are found in the clauses of English.

\subsection{System Network}

A complete system network involves organizing the choices into systems, and specifying how those choices are realized as structures (Eggins 2004: 200). This can be viewed in any system network of two bifurcations of Syntagmatic and paradigmatic. Language is said, in the wake of this, to be an arrangement of alternative resources. These are made known through the system network. The system network also goes further to indicate their realization in terms of structural constituents. Succinctly, it specifies the possible combinations available to be made in order to produce the descriptions of a class of linguistics items. The grammar of any language is entrenched and represented in its system network. Linking the stated idea with the levels of delicacy in the system, the arrangements of the choices in the network will have both simultaneous and hierarchical relationships that are open-ended (see Kress 1976:3-4). The system network is said to be the optional potential available to a language user. 'The system network allows us to map out the overall organization of the grammar of language' (Halliday \& Matthiessen 2004:7). Considering that position, one can see that the system network is a linear drawing with branches that discloses to the audience some variables and indices present in a processed text. The network in SFT contains the complete entity of the delicacy which is the main principle of ordering system variables relating one to another. The degree of details and specificity of the grammar of a language is exposed through the system network. The organization of the systemic choices is produced from left to right by a means of the entry condition. 
Linguistic system choices are actually abstract that one could pitch a tent in the political arena of the Federal Government of Nigeria, for instance, to illustrate a network of its hierarchical simultaneous offices in the system. See the figure below.

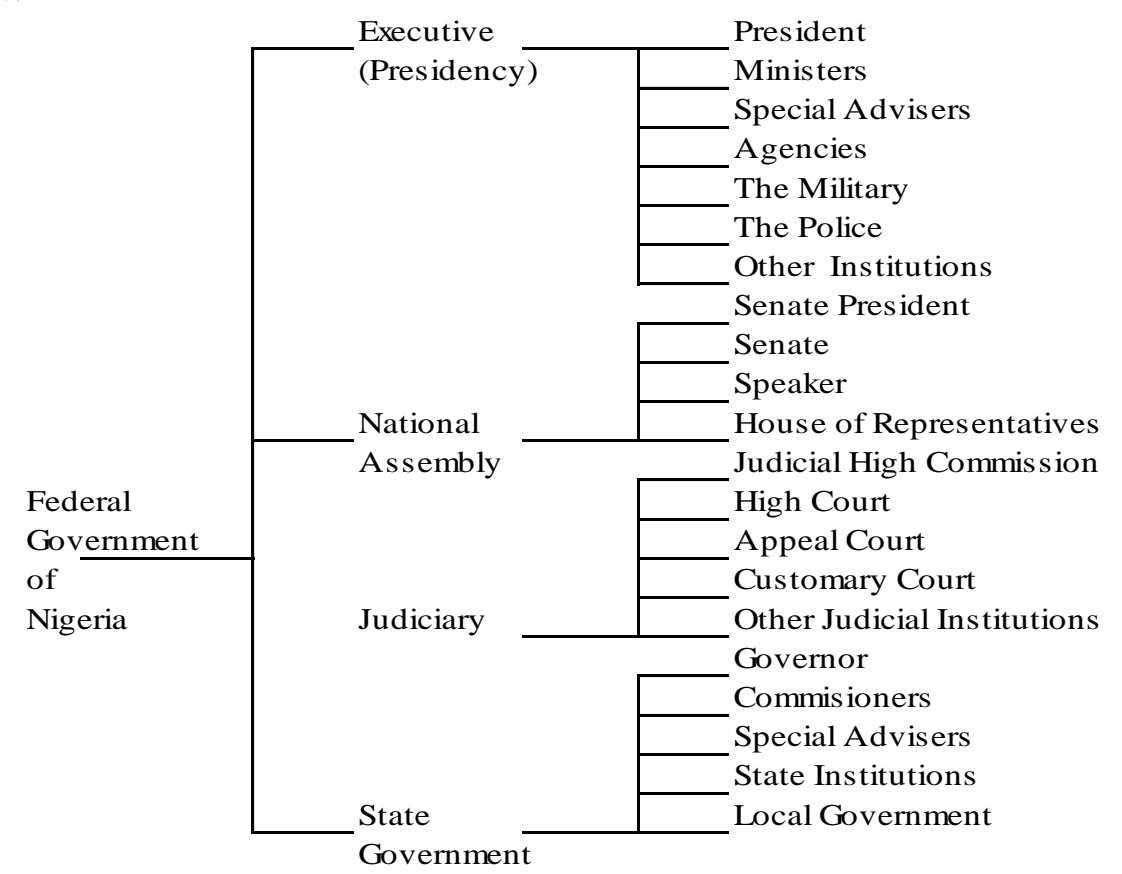

Figure 2. The System Network of the Federal Government of Nigeria

Figure 2 is a skeletal way of representing the system network of the Nigerian Government. It is drawn specifically from the left to right. It is hierarchically simultaneous. The choices are independent, yet, they have strong ties of relationships. They have their dominant constituents and at the same time reporting lines but the bulk stops at the table of the President who is the head of the government. The map is drawn to depict what is known as System Network in SFT. This knowledge could serve as the beginning of a positive reception of the system network in SFT. The map initiates from a point of entry and starts to yield the possible systemic alternatives. Apart from the linguistic science, the concept of the system network is a virile tool useful for realizing structural constituents in institutions where the simultaneous hierarchy is key and a necessity.

\subsection{The Three Metafunctions}

From a Saussurean Syntagmatic perspective, the structure of a clause is distributed into constituents. Halliday deciphers the same structure into semiotic slots in three systemic but paradigmatic vertical alternatives. This is done as a means of generating meanings. The meanings are achieved in terms of structural stratifications and social contents. These are a relevant source of classifying SFT as a theory with socio-cultural facilities of meaning potential. Halliday and Matthiessen explain that 'The clause is a composite entity. It is constituted not of one dimension of structure but three, and each of the three construes a distinctive meaning' (Halliday \& Matthiessen 2004: 60). The writer has mentioned earlier that, the clause is the hub of the textual analysis in SFT. It means then that, most of the linguistic analysis done is based on the clause. Surprisingly, Halliday and Matthiessen have said that three separate strands of meaning are distinctly derived from the clause through the applications of some systemic paradigms. These paradigms that assist in construing these strands of meaning are called the Three Metafunctions. 'The labels for each of the three metafunctions are reasonably transparent: the first is the experiential; the second is the interpersonal; and the third is the textual' (Thompson 2004: 30). The three metafunctions could be technically likened to the three tripod stands in the kitchen where a utensil is placed for cooking to take place. If one of the stands is broken or removed its presence will be greatly felt. There is a possibility that the cooking utensil may fall. This illustrates how the three metafunctions functionally operate. If one of the metafunctions is absent in the analysis, the meaning of a clause cannot be complete because they are just three different concepts that bring out three different meanings from one single clause. It is mentioned that,

Newcomers to functional grammar are sometimes confused by metafunctions because they expect them to operate independently and discretely. This is a mistaken expectation. In almost any instance of language, all three metafunctions operate simultaneous in the creation of meaning in relation to context. This is because certain aspects of the grammar support the ideational metafunction, other aspects realize the interpersonal metafunction, and yet others realize the textual metafunction (Bloor \& Bloor 2004: 11).

These remarks signal that some people encounter difficulties in knowing that the three systems realize meanings for the same purpose at the same time. The confusion is understandable because of the complexity of the metafunctions. At this juncture, the study has no option than to lift excerpts from Thompson in order to remove the likely hazy ineptitude that might have occurred in the classifications of the three metafunctions.

We can summarize the three kinds of meanings that we have so far identified in an informal way as follows.

We use language to talk about our experience of the world, including the worlds in our own minds, to describe events and states and entities involved in them. This is the Ideational Metafunction. 
We also use language to interact with other people, to establish and maintain relations with them, to influence their behavior, to express our own viewpoint on things in the world, and to elicit or change theirs. This is the Interpersonal Metafunction.

In using language, we organize our messages in ways that indicate how they fit in with the other messages around them and with the wider context in which we are talking or writing. This is the Textual Metafunction (Thompson 2004: 30).

By ideational metafunction, Thompson refers to the content of the message. That is, the concern of the clause - the goings-on. The interpersonal metafunction is about the roles the speaker and the addresser play in the interaction. In this case, there is a kind of attitudinal behavior that each of the interactants will possess. It is here that the issue of 'formality or familiarity' (Ravelli 2001: 44) will be expressed and experienced. In Thompson's view, the textual metafunction is reasonably the organization of the clause. It is the order of the elements in the message. The foregrounding or back-grounding of the message lies solely in the domain of the encoder when taking cognizance of the term, text, which serves as the communicative source. This is the choice available to the encoder in terms of the ordering of words.

From the grammatical perspectives: the ideational is transposed as TRANSITIVITY; the interpersonal is transposed as MOOD; and the textual is transposed as THEME. Each transposition represents the core of the message except for the THEME that has the RHEME as the core of the clause. From the contextual and discourse variability: the ideational or experiential is known as the Field of discourse; the interpersonal as the Tenor of discourse; and the textual as the Mode of discourse.

\subsection{Theoretical Slant}

As there are theoretical applications adopted for data analysis in physical sciences, so also the grammar of a language attracts theoretical framework for its systematic activities. Halliday and Matthiessen (1997: 21) explain that 'The grammar of a language is a very rich and complex system; the grammatics must bring out that richness and complexity, and not obscure it. This means recognizing the different vectors along which the complexity is ordered and exploring one step at a time.' From the foregoing, language is said to have so many different parts and to a large extent, these have made it to be a very difficult phenomenon of study. A relevant theory must be employed as an activating tool of performing a wide range of tasks for shredding the complexity of a language into understandable pieces. It is such an application that will assist the analysis to avert any unpleasant experience and to transcend any linguistic huddles. The 'arm of the grammar' (ibid.) employed as the conceptual framework for the analysis of text is the grammatical MOOD of English. As earlier discussed, the MOOD is the grammatical transposition of the interpersonal metafunction. The interpersonal metafunction takes into account the Mood component of a clause and the Residue. According to Daramola, it concerns the participants in the discourse, thereby presenting language on doing something by and to the people. It deals with the role relationship among the participants in a universe of discourse' (Daramola 2008: 357; see also Malmkjaer 2004).

Daramola submits that, language used in a context does something for the participating entities. Thus, the social relationship and cadre of the participants are featured greatly in the interpersonal metafunction. It exposes the readers to who does something, to whom and how does participant (A) relates his message to the other participant (B). From the semiotic address, the grammatical structures of this domain are the concepts of Subject, Finite, Modality, Fused Element and Residue. If one could still roll on the Daramola's hypothesis, one will say that 'Any attempt to provide a full description of the interpersonal metafunction... in this piece of work will be sheer oversimplification' (ibid.). The article summarizes the concept of the interpersonal metafunction in the system network as shown in Figure 3 below.

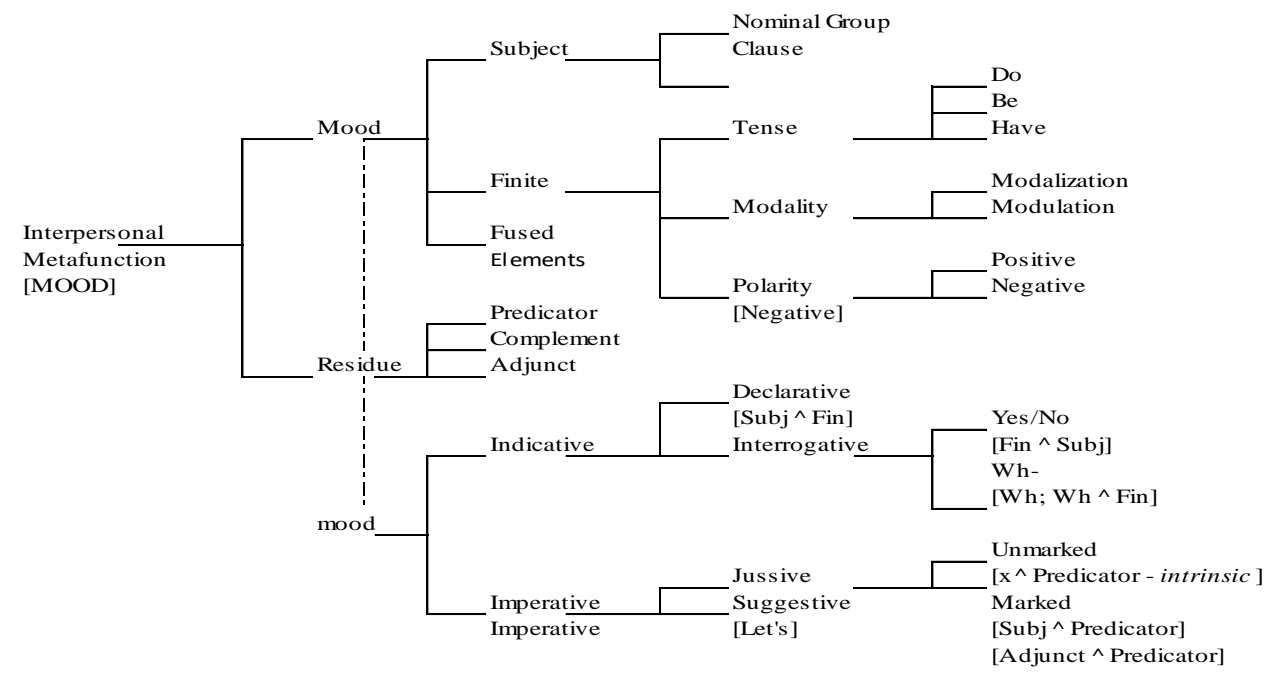

Figure 3. The mood system of English (Thompson 2004:58)

There are three types of Mood indicated in Figure 3. The first one begins with a capital ' $M$ ' and the second with a lower case ' $m$ '. The Mood indicates the Subject + Finite as a component of a clause. The mood indicates the basic patterns of a clause, that is, the basic choice of clause types in English. The third concept is in upper case. As earlier mentioned, it is the grammatical transposition of the mood system i.e. interpersonal metafunction. 


\section{Methodological Framework}

The data for this study is Psalm 1. This text is an excerpt from the Holy Bible, the New International Version (henceforth: NIV). It is presented in a clausal form and the number of clauses therein is indicated. Besides, the interpersonal metafunction is a systemic tool utilized to analyze all the clauses and later appreciated with statistical tools of table and graph for value deductions. Thereafter, the functional meaning are explicated from a contextual perspective through the Tenor of discourse.

\subsection{Presentation of Psalm 1 in Clauses}

1. Blessed is the man

2. who does not walk in the counsel of the wicked

3. or stand in the way of sinners

4. or sit in the seat of mockers.

5. But his delight is in the law of the LORD,

6. and on his law he meditates day and night.

7. He is like a tree planted by streams of water,

8. which yields its fruit in season

9. and whose leaf does not wither.

10. Whatever he does prospers.

11. Not so the wicked!

12. They are like chaff

13. that the wind blows away.

14. Therefore the wicked will not stand in the judgment,

15. nor sinners... in the assembly of the righteous.

\subsection{Analysis of Psalm 1}

\begin{tabular}{|l|l|l|}
\hline Blessed & is & the man \\
\hline Compl. & Finite & Subject \\
\hline Residue & Mood \\
\hline
\end{tabular}

\begin{tabular}{|l|l|l|l|l|}
\hline who & does not & walk & $\begin{array}{l}\text { in the } \\
\text { counsel }\end{array}$ & $\begin{array}{l}\text { of the } \\
\text { ungodly }\end{array}$ \\
\hline Subject & Finite & Predicator & Adjunct & Adjunct \\
\hline Mood & Residue \\
\hline
\end{tabular}

\begin{tabular}{|l|l|l|l|l|l|l|l|}
\hline or & stand & in the way & of sinners \\
\hline Conjunct. & Predicator & Adjunct & Adjunct \\
\cline { 2 - 6 } & Residue
\end{tabular}$\quad$\begin{tabular}{|l|l|l|l|} 
or & sit & in the seat & of mockers \\
\hline Conjunct. & Predicator & Adjunct & Adjunct \\
\hline
\end{tabular}

\begin{tabular}{|l|l|l|l|l|}
\hline But & his delight & is & in the law & of the LORD \\
\hline Conjunct. & Subject & Finite & Adjunct & Adjunct \\
\hline & Mood & Residue \\
\cline { 2 - 4 }
\end{tabular}

\begin{tabular}{|l|l|l|l|l|l|}
\hline and & on his law & he & meditates & day and night \\
\hline Conjuct. & Adjunct & Subject & Finite: Present & meditate: Predicator & Complement \\
\cline { 3 - 4 } & \multicolumn{3}{|c|}{ Residue } \\
\cline { 2 - 3 } & &
\end{tabular}

\begin{tabular}{|l|l|l|l|}
\hline He & is & like a tree planted & by the streams of water \\
\hline Subject & Finite & Adjunct & Adjunct \\
\hline Mood & Residue & \\
\hline
\end{tabular}

\begin{tabular}{|l|l|l|l|l|}
\hline which & yields & its fruits & in season \\
\hline Subject & Finite: Present & yield: Predicator & Compl. & Adjunct \\
\hline Mood & Residue & \\
\hline
\end{tabular}

\begin{tabular}{|l|l|l|l|}
\hline and & whose leaf & does not & wither \\
\hline Conjunct. & Subject & Finite & Predicator \\
\cline { 2 - 3 } & Mood & Residue \\
\cline { 2 - 3 }
\end{tabular}

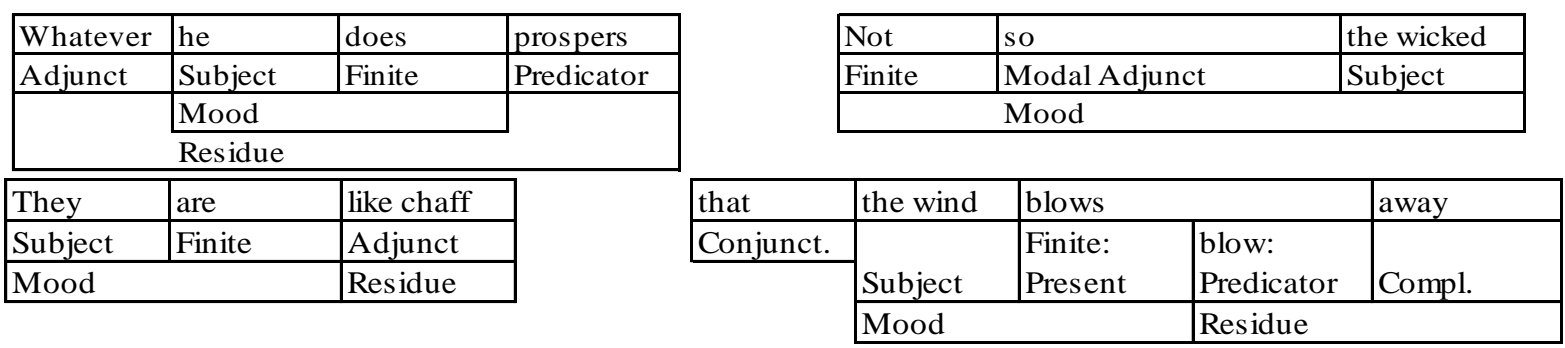

\begin{tabular}{|l|l|l|l|l|}
\hline Therefore & the wicked & will not & stand & in the judgement \\
\hline Conj. Adv. & Subject & Finite & Predicator & Adjunct \\
\hline
\end{tabular}

Figure 4. Mood system analysis of Psalm 1 
The analysis in Figure 4 is translated into table and graph in Figure 5 in order to show mood system elements recurrence values.

\begin{tabular}{|l|l|}
\hline Structural Class & Recurrence \\
\hline Mood & 13 \\
\hline Modality & 1 \\
\hline Moodless & 2 \\
\hline Modulated Inter. & 0 \\
\hline F. Declarative & 11 \\
\hline E. Declarative & 4 \\
\hline Imperative & 0 \\
\hline Interrogative & 0 \\
\hline Neg. Polarity & 7 \\
\hline
\end{tabular}

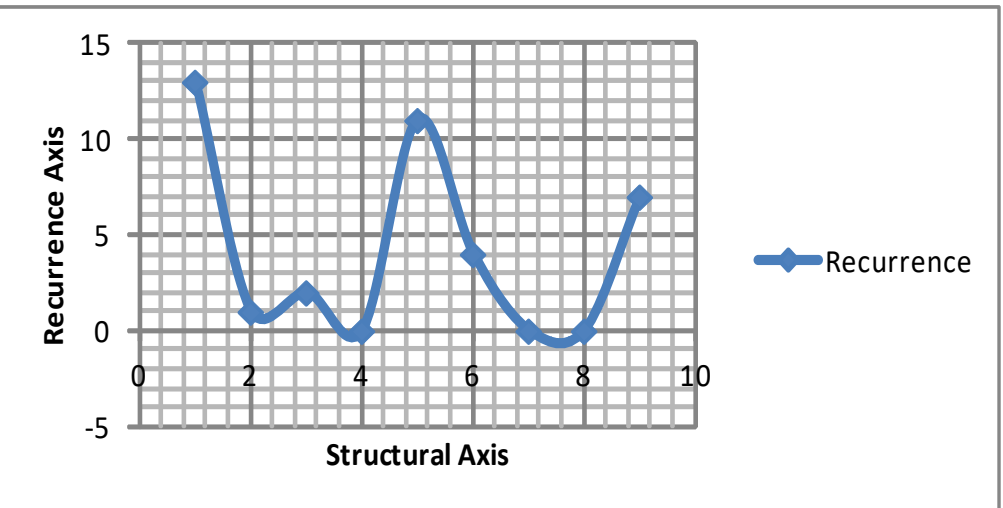

Figure 5. Structural class recurrence of Psalm 1

Mood records the highest value in Figure 5 which is followed by Full Declarative. However, both Imperative and Interrogative do not account for any point at all. By implications, Psalm One interacts with its audience through Subject-Finite relationships. The partnerships are polarized with negativity in order to demonstrate the feelings of the dramatis persona to those who are recalcitrant to the Psalmist's instructions. It is also an indicator of the capability of the Hallidayan grammatics to decipher linguistic structures and distribute them into various semiotic slots and categories.

\section{Results and Discussion}

The total clauses are analyzed for Mood in accordance with the descriptions given in the theoretical framework which is further elaborated in full-fledged in the mood system network in Figure 3. Figure 5 summarizes the results of the analysis of the Mood structural class, showing the organs of the clauses in their simple and digitized forms. One indicator in the text is that it is a negotiable piece yet there is no possibility of a feedback from the addresser. The table is accompanied with a graph to further show the values of the recurrent structures. The Mood structural elements recur as follows: Mood $=13$, Modality $=1$, Moodless $=2$, Modulated Interrogative $=0$, Full Declarative $=11$, Elliptical Declarative $=4$, Imperative $=0$, Interrogative $=0$ and Negative Polarity $=7$. The total clause is fifteen .

Systemicists (e.g. Ravelli 2000) have realized that the function that a language performs is more than just the content of the message. This notion comes to the limelight because a language does not function within the framework of only one person. The use of language occurs at least with two people. It takes two interactants to communicate either in the physical form or intrinsic appearance. So, language is seen as an interactive resource and a tool of communication. It is from this perspective that the Tenor of discourse in relation to a social context comes to the fore. Socially, every clause in language use is accompanied with role relationships and attitudes of the speaker and addresser. This is the nucleus of the interpersonal metafunction.

There are several grammatical resources that are relevant to this concept which assist in capturing the roles, relationships and attitudes of the interactants. Scholars have said that, in the role exchange the speaker/writer can be: giving goods and services (offer); giving information (statement); demanding goods and services (command); or/and demanding information (question). For exclusive discussions on this, see (Halliday \& Matthiessen 2004: 107-8; Ravelli 2000: 44-5; Thompson 2004: 46-8; Eggins 2004: 144-9; and Martin \& Rose 2003: 6-7). The speech functions (offer, statement, command and question) help identify the meaning of the clause. Each of these shows us the contributions that are made to the exchange.

The text, that is, Psalm 1 NIV Bible has all clauses as declaratives. It means that all the clauses are statements as pieces of advice to the addressee. They are soft and flexible. The speaker/writer is not imposing the message on the reader. The information passing across is not mandatory but optional. The pieces of advice could be accepted or rejected by the reader. It could be embraced or be thrown away into the bin. The nature of the message does not allow the other speech functions (offer, command and question) to be featured there. The tenor does not create strong boundaries between the writer and the reader. This flexible relationship is shown in all the clauses because there is no master-servant attitude in the message. For the nature of the message and for what the message intends to achieve, one would have expected one or two commands in it, yet, there is none.

In the structure, the Subject of the clause basically agrees with the main verb in person and in number. There are two kinds of Subject in the message: the ones used to refer to the righteous; and the ones used to reference the sinners. Let us consider the former first.

Blessed in the man; who does not work...; his delight is in the law of the LORD; ... he meditates day and night; $\boldsymbol{H e}$ is like a tree...; whose leaf does not wither; which yields its fruits in season; Whatever he does prospers.The Subject is a nominal group indicating in the first clause as the man. This is never repeated in the clause; it is further represented in pronoun forms. These are who, his delight, which and whose leaf. All the pronouns also agree with their main verbs. 
In the later, the Subject represents the followings: Not so the wicked; they are like chaff; Therefore the wicked will not stand in the judgment; nor sinners in the assembly of the righteous.

The Subject(s) are nominal group(s). They are indicated as the wicked, they and sinners. The only pronoun there is they. By and large, all the nominal group(s) agree with their main verbs.

The Mood of the clause comprises of both the Subject and Finite. Having discussed the Subject, the Finite could be examined from three distinct ways: in terms of Tense; in terms of Modality; and in respect of Fused Element (verb). The three verbal vectors are featured in the text.

Tense:

Who does not walk in the counsel...; his delight is in the law; he is like a tree; whose leaf does not wither; whatever he does prospers; they are like chaff.

There are three does not in the clauses which belong to the verbal operator in the tense of do. There are three is and one are which are verbal operators in the tense of be in active voices as signifiers of the present.

Modality:

Therefore, the wicked will not stand in the judgment...

The will not modality demonstrates politeness despite the fact that the action of the addresser is against the rule of the game of righteousness. It is not a sort of reducing or curtailing the distance between the persona and the consumer. However, a bit of hope is still given to the wicked probably he could just abide by the counsels of the writer. It shows the addresser's degree of tolerance and willingness to influence the addressee in spite of an identifiable added negative marker, $n o t$.

There are two negative polarities in the message. The second one is

Not so the wicked

These negative markers are employed to counteract all the positive things that are proposed as benefits for the righteous. Anywhere and anyhow they operate in a clause, the negative markers are also parts of the Finite of the clause.

Fused Element:

The last aspect of the Finite in this text is about the Fused Element. They are represented in the following ways:

and on his law he meditates day and night

which yields its fruit in season

that the wind blows away

The three clauses have the Finite in a fused relationship with the lexical verb. It is imperative to the analyst to find a means of separating them from being integrated. The case here is that the Finite is fused with the simple present of the lexical verb. As already shown in the analysis, the organs are detached thus;

meditates $=$ Finite $($ Present $)+$ meditate

yields $=$ Finite $($ Present $)+$ yield

blows $=$ Finite $($ Present $)+$ blow

The mood, that is, the basic choice of clause types in the data is not in variants. It reveals only one type. It has been said earlier that the text has only the declaratives. When one examines it from below, it gives the Subject ^ Finite structures. However, for the religious nature of the text from the NIV Bible, there is a strange structure of the indicatives as Finite ${ }^{\wedge}$ Subject. This structure is unusual in a declarative clause. Finite ${ }^{\wedge}$ Subject structure is linguistically known to be the interrogative. Some of them occur thus;

Blessed is the man (Finite ${ }^{\wedge}$ Subject)

Not so the wicked (Finite ${ }^{\wedge}$ Subject)

These clauses indicate that in a religious data, the linguistic behavior of texts may not follow the normal scientific codes and norms. It is important to understand that some of the religious texts could be poetic sometimes. These two clauses are 'a sort of' inverted statements. The Finite ${ }^{\wedge}$ Subject is a known structure of an interrogative clause as suggested in the clause elucidation in the review of literature.

There are also elliptical declaratives in the clauses, they appear thus,

1. or stand in the way of sinners

2. or sit in the seat of mockers

3. Not so the wicked

4. sinners in the assembly of the righteous

The examples 1, 2 and 4 are not imperatives yet because there are no Finite(s) in them. These are declarative complex clauses that have their Finite(s) in the preceding clauses. Clauses 1 and 2 are meant to be:

who does not stand in the way of sinners

who does not sit in the seat of mockers 
Both the Subject and Finite are ellipted from the clauses which make them to appear as the imperative but they are not. Clause 4 is supposed to be read as

sinners will not stand in the assembly of the righteous

The italicized element has been ellipted from the clause. Clauses 1 and 2 are ellipted from the initial position while clause 4 is ellipted from the medial position. The Finite is is ellipted from the clause 3 . Though inverted, the clause is supposed to read thus,

The wicked is not so

This declarative is ellipted also from the medial position as in clause 4 above.

It is shown from the analysis that, the Tenor of discourse is an informal type with dominant full declarative clauses. There are also few elliptical structures which are also accompanied with a low level of modality. Besides that, the writer demonstrates flexibility in the message; the dramatis persona also acts as someone who seems to know all things by portraying the spirit of understanding in terms of what accomplishes the righteous and what accomplishes the wicked in a constant manner. The writer shows as an individual who has the acute knowledge of the aftermath of human behaviors (righteousness and wickedness). The persona claims to have wisdom about today and the future of the two sets of the individual as reflected in the data's textual patterns.

The core of the interpersonal metafunction is the Mood which is the main component of a clause. It is expressed in the Subject + Finite. The remaining constituent of the clause is the Residue (Bloor \& Bloor 2004: 48-52). The Residue comprises of the Predicator + Complement + Adjunct. The Predicator is the verbal element (non-Finite) that follows after the Finite. Both the Complement and Adjunct provide additional information on the message of the clause. These structural elements are shown in the analysis despite that they are not within the scope of this study. (Mcgregor 1992: 139-142; Halliday \& Matthiessen 2004: 121-5; and Thompson 2004: 60-5) are good resources on the subject of the enquiry.

\section{Conclusion}

The study reveals the mood (i.e. Subject + Finite) as the functional domain of Psalm 1. The utilization of Full Declarative in Figure 5 illustrates the result further. Of significance is the deployment of the Negative Polarity. Its recurrence gives a bad signal about the feelings of the narrator about the disobedient. Nevertheless, both imperative and interrogative clauses could not function in the data, Psalm 1, which seem to portray a king of willingness to the audience regarding the message propagated. In other words, the message is optional and under compulsion for anyone. There are neither commands nor questions.

With the analysis done on this text so far, the author has demonstrated that SFT is a ductile linguistic tool of textual analysis. The text of Psalm 1 is inclined with both a poetic and day-to-day language, yet, SFT explicates it. The malleability of the SFT is exhibited from the perspective of the mood, which indicates the basic patterns of the clause. The mood in English can either be indicative or imperative. It is from these vectors that a linguistic choice can be properly made. Logically, if a choice is made from the indicative, the selection can only be from either the declarative or interrogative. From the other vector, that is, the imperative, if a choice is selected; it can only be done from either the jussive or suggestive perspective. Therefore, as long as the mood is a concept in SFT there can hardly be a text that does not fall into this domain either an analyst examines it syntagmatically from above and from around or paradigmatically from below. However, it is observed that some of the structure in the Psalm function as inverted linguistic elements of meaning making

\section{References}

Akere, F. (1990). English across disciplines: A use of English course Text. Ikeja, Lagos: Punmark Educational Limited.

De Beaugrande R. (1991). Linguistic theory: The discourse of fundamental works. London andNew York: Longman

Bloor, T. and Bloor, M. (2004). The functional analysis of English. Great Britain: Hodder Arnold.

Daramola, A. (2008). A child of necessity: A analysis of political discourse in Nigeria. Pragmatics: Quarterly Publication of The International Pragmatics Association. 18(3),355-360.

Davidse, K. (1992). Transitivity/ergativity: the janus-headed grammar of actions and events. Advances in systemic linguistics: Recent theory and practice. London: Pinter Publisher, 105 - 129.

Egbe, D. I. (1996a). Mastering English usage and communication skills. Lagos: Tisons Limited.

--- (1996b). Excellence in written and spoken English. Lagos: Longman Group.

Eggins, S. 92004). Introduction to Systemic Functional Linguistics. London: Continuum.

Fawcett, Robin P. (2000). A theory for Systemic Functional Linguistics. London: John Benjamins.

Firth J. R. (1957). Papers in linguistics 1934-1951. London: Oxford University Press

Halliday M.A.K. (1985a). Systemic background. Systemic perspectives in discourse, 1. Selected Theoretical papers from $9^{\text {th }}$ Interactional Systemic Workshop. Norwood, New Jersey: Ablex Publishing Corporation.

- - - (1985b). An ntroduction to Functional Grammar. Great Britain: Arnold. 1985. Print. 
- - - \& Hasan, R. (1976). Cohesion in English. Edinburgh: Pearson.

- - - (1985). Language, context, and text: Aspects of language in a socio-semiotic perspective. Geelong: Deakin University Press.

- - - (1992). How do you mean? Advances in systemic linguistic: Recent theory and practice. London: Pinter Publisher. (1992): 20 - 36. Print.

- - - \& Matthiessen M. I. M. Christian (1992). Construing experience through meaning: A language based approach to cognition. London: Cassell Academic. 1999. Print.

- - - (2004). An Introduction to Functional Grammar. Great Britain: Hodder Arnold.

Hudson, Richard A. 1996. Sociolinguistics. Cambridge: Cambridge University Press.

Kress, G. (1981). Halliday: system and function in language. London: Oxford University Press.

Lemke, J. L. (1995). Textual politics: Discourse and social dynamics. Oxon: Taylor \& Francis.

Malmkjaer, K. (ed.) (2004). The linguistics encydopedia. London: Routledge.

Martin, J. R. (1992). English text: Structure and system. Philadephia: John Benjamins.

- - - \& Rose D. (2005). Working with discourse: Meaning beyond the clause. New York: Continuum.

Mcgregor W. (1992). The place of circumstantial in Systemic-Functional Grammar. Advances in systemic linguistics: Recent theory and practice. London: Pinter Publisher, 136-145.

Matthiessen, C. (1992). Interpreting the textual metafunction. Advances in systemic linguistics, recent theory and practice. London: Pinter Publisher, 37 - 80.

Ravelli L. (2000). Getting started with functional analysis of texts. Researching language in schools and communities. London: Cassel, 1, 27 - 63.

Schiffrin, D., Tannen, D., \& Hamilton, H. E. (eds.) (2002). The handbook of discourse analysis. New York: Blaclwell Publishing.

Trask, R. L. and Stockwell, P. (2008). Language and linguistics: The key concepts. New York: Routledge.

Thompson, G. (2004). Introducing Functional Grammar. Great Britain: Hodder Arnold.

Unworth, L. \& Frances C. (2000). Developing socially responsible language research. Researching language in schools and communities. London: Cassell , 1-26..

Yule, G. (1985). The study of language. Cambridge: Cambridge University Press.

\section{Internet Resources}

Chapelle, A. C. (1998). Some notes on Systemic Functional Linguistics: English/Linguistics October $28,1998$. Retrieved from www. Public. Iastate.edu/ ${ }^{c}$ arolc/LING511/sfl.html. 